\title{
Comparison of Single Doses of Amoxicillin or of Amoxicillin- Gentamicin for the Prevention of Endocarditis Caused by Streptococcus faecalis and by Viridans Streptococci
}

\author{
P. Francioli, P. Moreillon, \\ and $M$. P. Glauser
}

From the Division of Infectious Diseases, Department of Internal Medicine, Centre Hospitalier Universitaire Vaudois,

Lausanne, Switzerland

\begin{abstract}
Recent recommendations for the prophylaxis of endocarditis in humans have advocated single doses or short courses of antibiotic combinations ( $\beta$-lactam plus aminoglycoside) for susceptible patients in whom enterococcal bacteremia might develop or for patients at especially high risk of developing endocarditis (e.g., patients with prosthetic cardiac valves). We tested the prophylactic efficacy (in rats with catheter-induced aortic vegetations) of single doses of amoxicillin plus gentamicin against challenge with various streptococcal strains (two strains of Streptococcus faecalis, one of Streptococcus bovis, and three of viridans streptococci); we then compared this efficacy with that of single doses of amoxicillin alone. Successful prophylaxis against all six strains was achieved with single doses of both amoxicillin alone and amoxicillin plus gentamicin. This protection, however, was limited, for both regimens, to the lowest bacterial-inoculum size producing endocarditis in $90 \%$ of control rats and was not extended to higher inocula by using the combination of antibiotics. We concluded that a single dose of amoxicillin alone was protective against enterococcal and nonenterococcal endocarditis in the rat, but that its efficacy was limited and could not be improved by the simultaneous administration of gentamicin.
\end{abstract}

Recommendations of the American Heart Association for antibiotic prophylaxis of bacterial endocarditis are partly based on studies in rabbits [1]. In these experiments the bacterial inocula used for inducing endocarditis were very high; probably one or several logs higher than the minimum inocula necessary to induce endocarditis in $90 \%$ of untreated animals $\left(\mathrm{ID}_{90}\right)[2,3]$. Under these circumstances, only high and prolonged levels of bactericidal antibiotics were effective in preventing endocarditis. Hence, recommendations for the prophylaxis of endocarditis in humans have advocated multiple doses of bactericidal antibiotics or combinations of antibiotics. These recommendations have been somewhat cumbersome and often difficult to comply with, both for physicians and for patients.

Received for publication September 21, 1984, and in revised form December $27,1984$.

This work was presented in part at the Interscience Conference on Antimicrobial Agents and Chemotherapy, October 4-6, 1982, held in Miami, Florida.

This work was supported by grant no. 3.847 .083 from the Swiss National Foundation for Scientific Research.

Please address requests for reprints to Dr. M. P. Glauser, Division of Infectious Diseases, Centre Hospitalier Universitaire Vaudois, 1011 Lausanne, Switzerland.
Because it has been argued that high inocula are not relevant to clinical situations [4], recent experiments in rats have analyzed in detail the role of the size of the bacterial inoculum used to induce endocarditis on the effectiveness of prophylactic antibiotics. By using various strains of streptococci that commonly cause endocarditis, it was found that various antibiotics (including amoxicillin, penicillin, and even bacteriostatic antibiotics such as clindamycin or erythromycin), given as single doses, were effective in preventing endocarditis, provided that the inoculum size used to induce endocarditis was not higher than the $\operatorname{ID}_{90}[5,6]$. Recently, recommendations for the prophylaxis of endocarditis using single doses of antibiotics in humans have emerged [7]. Although these recommendations are obviously more practical than those for multiple doses, it is not known whether they are appropriate.

To improve the efficacy of the single dose regimens, the use of combinations of antibiotics instead of a single drug has been proposed, particularly when enterococci are considered to be potential pathogens [7] ( $\beta$-lactam antibiotics are only bacteriostatic against these bacteria unless combined with an aminoglycoside [8]). The purpose of the present experiments was to compare the efficacy of single doses 
of amoxicillin with that of the combination of amoxicillin and gentamicin.

\section{Materials and Methods}

Microorganisms. Six strains of streptococci were used for these experiments; all were isolated from patients with endocarditis. Three strains were group D streptococci: two were identified as Streptococcus faecalis (nos. 309 and 1209) and one as Streptococcus bovis. Three strains were of the viridans group and were identified as Streptococcus mitis, Streptococcus intermedius, and Streptococcus sanguis (the latter two strains have been used in previous experiments $[5,6])$.

Determination of MICs, MBCs, and rates of killing. The MICs of amoxicillin and of gentamicin were determined for the six microorganisms by using a standard broth-dilution technique with an inoculum of $10^{6}$ organisms from an overnight culture [9].

The MBCs were determined by subculturing on blood-agar plates supplemented with penicillinase (Difco Laboratories, Detroit) 10-fold and 100-fold broth dilutions of a 0.1-ml sample from each dilution of antibiotic showing no turbidity after $18 \mathrm{hr}$ of incubation. This dilution procedure, before subculturing for $\mathrm{MBC}$ determination, was used to avoid the carryover of antibiotic, a phenomenon that can give falsely low MBCs. After incubation for $48 \mathrm{hr}$, the number of colonies from each subculture on blood-agar plates was counted and the MBC determined as the lowest dilution of antibiotic that showed $99.9 \%$ killing.

Using concentrations of $25 \mu \mathrm{g}$ of amoxicillin $/ \mathrm{ml}$ or $8 \mu \mathrm{g}$ of gentamicin $/ \mathrm{ml}$ or both, we determined the rates of killing of the six strains in tryptic soy broth (Difco) by using a $10^{6}$ inoculum from an overnight culture. Concentrations of $25 \mu \mathrm{g}$ of amoxicil$\mathrm{lin} / \mathrm{ml}$ and of $8 \mu \mathrm{g}$ of gentamicin $/ \mathrm{ml}$ were chosen because they were similar to serum levels achieved in rats $30 \mathrm{~min}$ after the iv injection of $40 \mathrm{mg}$ of amoxicillin $/ \mathrm{kg}$ and $4 \mathrm{mg}$ of gentamicin $/ \mathrm{kg}$. In man, these serum levels are achieved $2 \mathrm{hr}$ after an oral dose of $3 \mathrm{~g}$ of amoxicillin [10] and $30 \mathrm{~min}$ after an iv dose of $1.5 \mathrm{mg}$ of gentamicin $/ \mathrm{kg}$ [11]. Against $S$. bovis, a concentration of $2 \mu \mathrm{g}$ of gentamicin $/ \mathrm{ml}$ was used because the strain was killed too rapidly by $8 \mu \mathrm{g} / \mathrm{ml}$ to allow the demonstration of synergism when the gentamicin was combined with amoxicillin. At various times after the inoculation of bacteria into the antibiotic-containing broth, $10^{-1}, 10^{-3}$, and $10^{-5} \mathrm{di}-$ lutions of a 0.1-ml sample were subcultured on blood- agar plates containing penicillinase and were incubated for $48 \mathrm{hr}$ for colony counts.

Serum levels of antibiotics and serum bactericidal activity. Serum levels at $30 \mathrm{~min}, 1,2$, and $4 \mathrm{hr}$ after injection of various iv doses of amoxicillin or gentamicin to groups of five rats were determined by the standard agar-diffusion technique with $\mathrm{Ba}$ cillus subtilis as the test organism and normal rat serum as diluent [12]. The serum bactericidal activity $30 \mathrm{~min}, 1,2$, and $4 \mathrm{hr}$ after the iv administration of amoxicillin (or amoxicillin plus gentamicin) to rats were determined for each strain by standard methods with a $10^{5}$ inoculum of an overnight culture [13]. The serum bactericidal activity was defined as the highest serum dilution providing $99.9 \%$ killing after $18 \mathrm{hr}$ of incubation.

Production of endocarditis and evaluation of infection. Sterile vegetations were produced in female Wistar rats (180-200 g) by a modification of a method already described [14]. Briefly, a polyethylene catheter (PP 10; Portex, Hythe, Kent, England) was inserted across the aortic valve through the right carotid artery and secured with a silk ligature. Twenty-four hours after catheterization rats were injected in the tail vein with $0.5 \mathrm{ml}$ of saline containing various inocula (confirmed by colony counts and expressed in cfu) from overnight cultures of the test microorganisms. Rats were killed $72 \mathrm{hr}$ thereafter, and aortic vegetations were excised, weighed, homogenized in $1 \mathrm{ml}$ of saline, serially diluted, and plated on blood-agar plates containing penicillinase. Plates were counted after $48 \mathrm{hr}$ of incubation at $37 \mathrm{C}$. This method permitted the detection of $10^{2} \mathrm{cfu} / \mathrm{g}$ of vegetation.

Prophylaxis of endocarditis with amoxicillin or with amoxicillin plus gentamicin. For each inoculum size equal to or greater than the $\mathrm{ID}_{90}$ of a particular strain tested, $30-40$ rats were divided into three groups: the first group received $40 \mathrm{mg}$ of amoxicillin alone $/ \mathrm{kg}$ (iv) $30 \mathrm{~min}$ before bacterial challenge; the second group received the combination of amoxicillin and $4 \mathrm{mg}$ of gentamicin $/ \mathrm{kg}$ (im); and the control group received saline (iv).

Statistical evaluation. The $\chi^{2}$ test with Yates's correction and the unpaired Student's $t$ test were used for statistical comparisons.

\section{Results}

Minimum inhibitory and bactericidal concentrations. The MICs and MBCs of amoxicillin for the six test organisms are shown in table 1. All strains 
Table 1. MICs and MBCs of the six test organisms.

\begin{tabular}{llrrrr}
\hline & \multicolumn{2}{c}{ Amoxicillin } & & \multicolumn{2}{c}{ Gentamicin } \\
\cline { 2 - 3 } \cline { 5 - 6 } Strains & MIC & MBC & & MIC & MBC \\
\cline { 5 - 6 } S. faecalis 309 & 1 & $>128$ & 32 & 64 \\
S. faecalis 1209 & 1 & $>128$ & 4 & 16 \\
S. bovis & 0.032 & $>128$ & & 1 & 2 \\
S. mitis & 0.016 & $>128$ & & 16 & 32 \\
S. intermedius & 0.125 & $>128$ & & 8 \\
S. sanguis & 0.008 & 16 & 8 & 32 \\
\hline
\end{tabular}

NOTE. Results are $\mu \mathrm{g}$ of the antibiotic/ $\mathrm{ml}$.

had high MBCs, a phenomenon that is common among streptococci when careful measures are taken to avoid the carryover of antibiotics (P. Meylan, P. F., and M. P. G., unpublished observations; [15]).

Serum levels of amoxicillin and of gentamicin in rats. Following the iv administration of various doses of amoxicillin, it was found that $40 \mathrm{mg} / \mathrm{kg}$ gave a mean peak serum level $( \pm$ SD) of $23.7 \pm 3.0$ $\mu \mathrm{g} / \mathrm{ml}$ at $30 \mathrm{~min}$. This level was similar to those achieved in humans following an oral dose of $3 \mathrm{~g}$ of amoxicillin [10]. The mean values ( \pm SD) at 1 , 2,4 , and $6 \mathrm{hr}$ after iv injection into five rats were $8.8 \pm 1.0 \mu \mathrm{g} / \mathrm{ml}, 3.5 \pm 0.4 \mu \mathrm{g} / \mathrm{ml}, 0.6 \pm 0.3 \mu \mathrm{g} / \mathrm{ml}$, and zero, respectively.

Following the im administration of $4 \mathrm{mg}$ of gentamicin $/ \mathrm{kg}$, serum levels $( \pm \mathrm{SD}$ ) were $8.0 \pm 2.1$ $\mu \mathrm{g} / \mathrm{ml}, 4.6 \pm 1.8 \mu \mathrm{g} / \mathrm{ml}, 1.9 \pm 0.9 \mu \mathrm{g} / \mathrm{ml}$, and zero, $30 \mathrm{~min}, 1,2$, and $4 \mathrm{hr}$ after injection, respectively.

Serum bactericidal activities. Following the iv administration of $40 \mathrm{mg}$ of amoxicillin $/ \mathrm{kg}$ to rats, no serum bactericidal activities (five determinations) against any of the six strains of streptococci could be detected $30 \mathrm{~min}$ or later after injection. After administration of a combination of amoxicillin ( 40 $\mathrm{mg} / \mathrm{kg}$ ) and gentamicin $(4 \mathrm{mg} / \mathrm{kg})$, the serum bactericidal activities (mean of five determinations) against the three group D strains were 1:8, 1:4, and undetectable, at $30 \mathrm{~min}, 2$, and $4 \mathrm{hr}$, respectively. Against the three viridans strains, they were $1: 4,1: 2$, and undetectable at the same time points.

Rates of killing of the six test strains. With concentrations of $8 \mu \mathrm{g}$ of gentamicin alone/ml, only the S. bovis inoculum was killed in $6 \mathrm{hr}$, the remaining five strains showed $>100 \%$ survival of the inoculum at $24 \mathrm{hr}$. Using $2 \mu \mathrm{g}$ of gentamicin/ml against S. bovis, we observed no significant killing over 24 hr. Figure 1 represents the rates of killing of the six strains by $25 \mu \mathrm{g}$ of amoxicillin $/ \mathrm{ml}$ with and without the addition of $8 \mu \mathrm{g}$ of gentamicin ( $2 \mu \mathrm{g}$ of gentamicin for $S$. bovis). The figure shows that no significant killing occurred during the first $6 \mathrm{hr}$ of exposure to amoxicillin for any of the six strains. As with gentamicin alone, no strain was killed upon $24 \mathrm{hr}$ of exposure to amoxicillin. In contrast, when exposed to $25 \mu_{\mathrm{S}}$ of amoxicillin $/ \mathrm{ml}$ and $8 \mu \mathrm{g}$ of gentamicin $/ \mathrm{ml}$ $\left(2 \mu_{\circ} / \mathrm{ml}\right.$ for $S$. bovis), killing of more than $99.9 \%$ of the inoculum (which defines the $\mathrm{MBC}$ and the serum bactericidal activity) was achieved in less than $6 \mathrm{hr}$ for the six strains, thus demonstrating synergism upon exposure to the combination of amoxicillin and gentamicin at this time point. It took more

Figure 1. Rates of in vitro killing of six streptococcal strains by $25 \mu \mathrm{g}$ of amoxicillin alone (amoxi) $/ \mathrm{ml}$ or in combination with $8 \mu \mathrm{g}$ of gentamicin (genta) $/ \mathrm{ml}$. (1) S. faecalis 309 ; (2) S. faecalis 1209; (3) S. bovis; (4) S. mitis; (5) S. sanguis; and (6) $S$. intermedius.

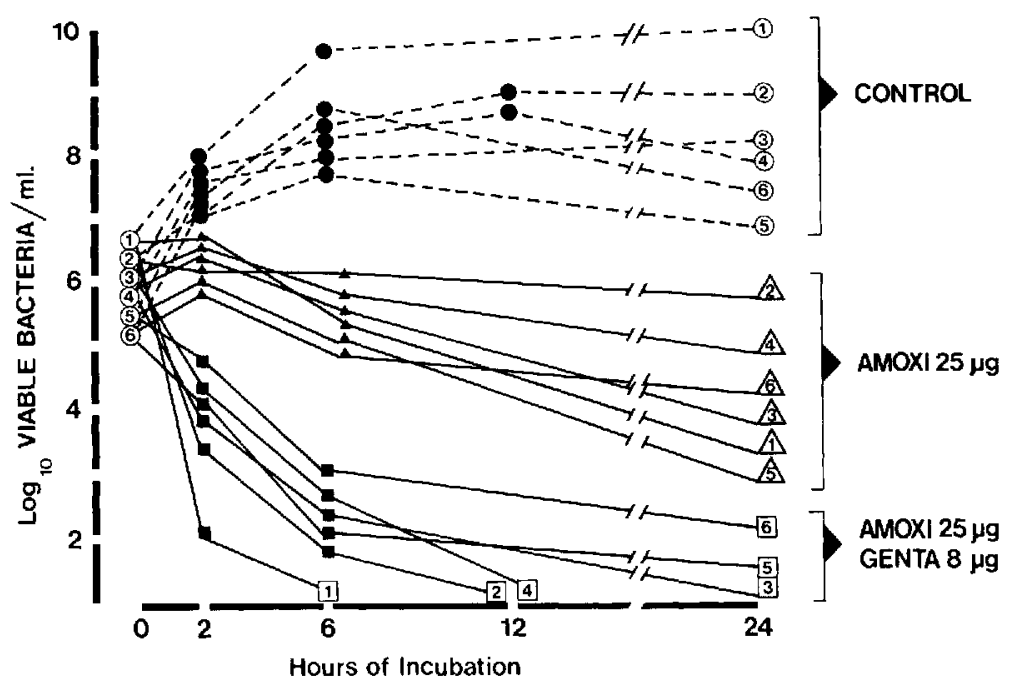




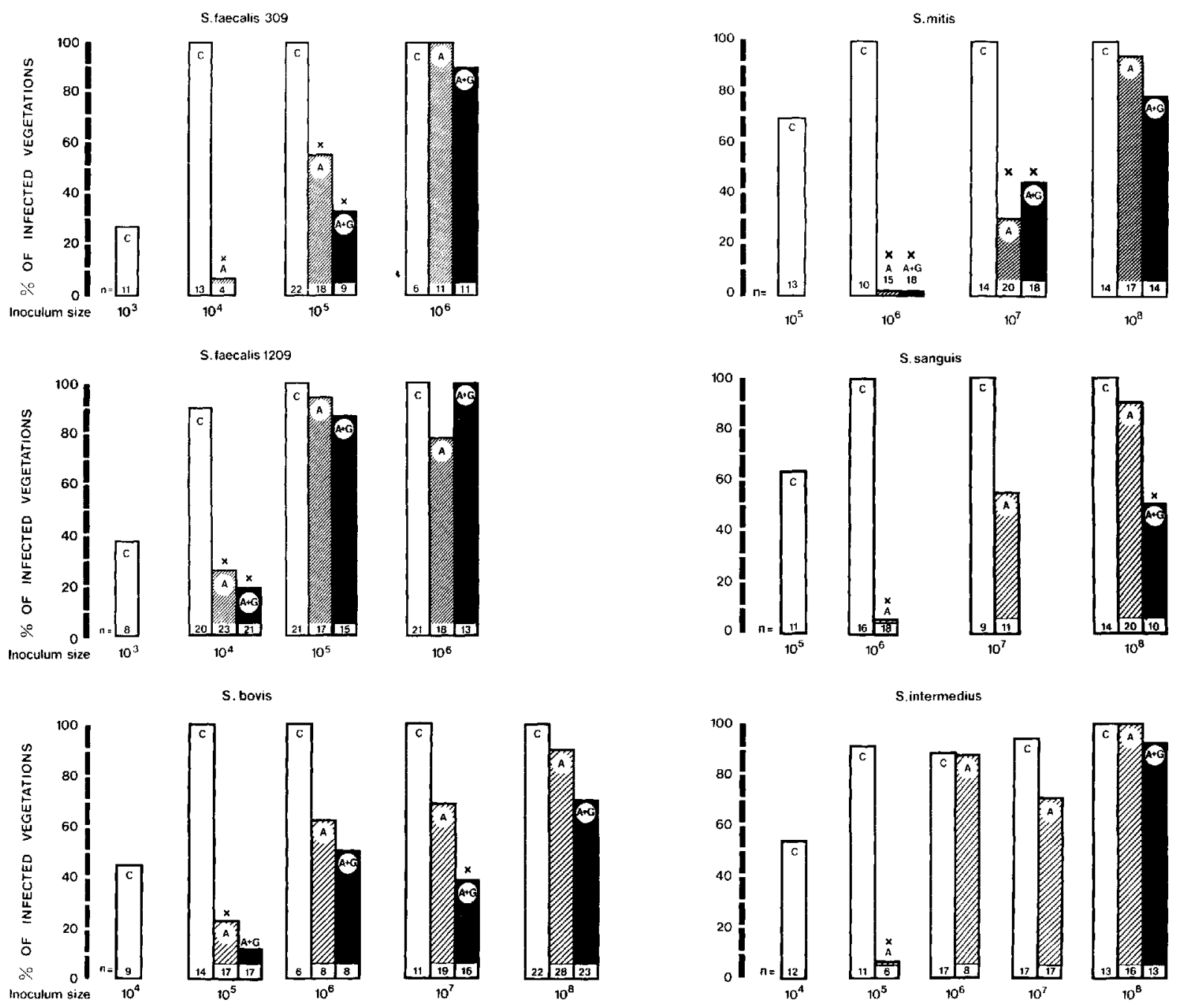

Figure 2. Incidence of endocarditis in control $(C)$ rats and in rats treated with amoxicillin (A) or amoxicillin + gentamicin $(A+G)$ three days after bacterial challenge with various inocula of six streptococcal strains. The total number of rats per group is indicated at the base of each column. $P$ values were calculated by $\chi^{2}$ analysis with Yates's correction; the cross symbolizes $P<.05$.

than $6 \mathrm{hr}$, however, for the combination of antibiotics to achieve sterility with five of the six strains.

Natural history of streptococcal endocarditis and prophylaxis with amoxicillin and gentamicin, alone or in combination. As shown in figure 2 , the incidence of endocarditis in control rats increased with the inoculum size of each strain used for challenge. The ID ${ }_{90}$ varied according to the strain tested; it was $10^{4} \mathrm{cfu}$ for the two $S$. faecalis strains, $10^{5} \mathrm{cfu}$ for S. intermedius and $S$. bovis, and $10^{6} \mathrm{cfu}$ for S. sanguis and $S$. mitis. With these inoculum sizes, amoxicillin alone completely prevented endocarditis. With inocula 10 times higher than the $\mathrm{ID}_{90}$, significant but insufficient protection was still observed, but for only two of the six strains (S. faecalis 309 and S. mitis).
With greater inocula, the prophylactic effect was overcome for all six strains. Despite in vitro synergism and increased serum bactericidal activity after simultaneous administration, the association of amoxicillin and gentamicin was not more effective than amoxicillin alone in preventing endocarditis caused by four of the six strains. For $S$. sanguis and S. bovis, the combination of the antibiotics was marginally better than amoxicillin alone.

\section{Discussion}

Recently, single doses of antibiotics like amoxicillin have been shown to be very effective in preventing experimental streptococcal endocarditis, provided 
that the inoculum sizes used to induce the bacteremia were not higher than the lowest inoculum capable of producing endocarditis in $90 \%$ of control animals [6]. Moreover, the protection conferred by antibiotics occurred in the absence of bacterial killing [6]. Indeed, even bacterostatic antibiotics like clindamycin and erythromycin were very effective in preventing endocarditis [5]. It was therefore of interest to investigate the efficacy of single doses of amoxicillin in preventing endocarditis induced by $S$. faecalis, a species of organism for which $\beta$-lactam antibiotics are known to be only bacteriostatic [8]. These experiments were performed in comparison with other streptococci, including three strains of the viridans group and one strain of $S$. bovis, which, like the enterococci, originate from the gut flora but differ from $S$. faecalis by their antibiotic susceptibility.

The results of the present experiments show that a single dose of amoxicillin alone prevented enterococcal endocarditis as effectively as it did nonenterococcal streptococcal endocarditis, provided that the inoculum used for challenge was not higher than $\mathrm{ID}_{90}$ for each strain tested. It should be noted, however, that the $\mathrm{ID}_{90}$ of the two $S$. faecalis strains were 10-100-fold lower than were the $\mathrm{ID}_{90}$ of the four other streptococcal strains tested, thus showing that the protection conferred by a single dose of amoxicillin against endocarditis caused by $S$. faecalis was limited to inocula of a lesser magnitude. This might explain why single doses of ampicillin alone were not effective in prior experiments in rabbits for the prophylaxis of enterococcal endocarditis in which the animals were challenged with only very high inocula [16].

It was remarkable that the protection observed in the present experiments occurred despite the absence of killing against the six strains tested, both in vitro and in vivo. Indeed, the killing curves showed that no strains were killed after $24 \mathrm{hr}$ of incubation in concentrations of amoxicillin similar to peak concentrations obtained in humans after oral administration of a 3-g dose. Moreover, there was no serum bactericidal activity detectable at the time of injection of the bacteria. Therefore, the present results that demonstrate the prophylactic efficacy of amoxicillin despite the absence of significant killing confirm our previous results with viridans streptococci $[5,6]$ and extend these observations to group D streptococci, especially to $S$. faecalis. Tolerance to the bactericidal action of cell wall-active antibiotics is not only a characteristic of $S$. faecalis but also appears to be a common finding among viridans streptococci isolated from patients with endocarditis. Indeed, among 25 viridans strains isolated from such patients, 17 were shown to be tolerant to amoxicillin (MBC/MIC ratio >32) and $13(50 \%)$ had MBCs $>32 \mu \mathrm{g} / \mathrm{ml}[15]$.

In the prophylaxis of endocarditis, experiments in rabbits $[16,17]$ have suggested that single doses of synergistic combinations of antibiotics might be more effective than a single dose of a single antibiotic in preventing streptococcal endocarditis, both of the viridans and of the enterococcal groups. This apparently contradicts the present experiments, in which single doses of the combination of amoxicillin and gentamicin were not superior to amoxicillin alone for four of the six strains tested and were only marginally better for the other two strains tested.

Several factors can account for these differences. First, in the rabbit experiments mentioned above, in which a single dose of ampicillin alone was ineffective in the prevention of enterococcal endocarditis, the combination of ampicillin and gentamicin was not uniformly efficacious; it was protective against only two of the four strains tested in detail [16]. Similarly, Guze et al. [18] found that three doses of the combination of ampicillin and gentamicin were not superior to ampicillin alone for two of the four strains tested and were only marginally better for the other two strains. Thus the combination of ampicillin and gentamicin, given either as single doses or even as short courses (three doses), were not reliably superior to ampicillin alone in preventing enterococcal endocarditis in rabbits.

Second, our previous [6] and present experiments have stressed the critical role of the size of the bacterial inoculum used for testing the efficacy of antibiotics. This is not only well illustrated by the success of antibiotic prophylaxis at or around the $\mathrm{ID}_{90}$, but also by its failure when the inoculum size is increased. Thus, in order to compare different prophylactic antibiotic regimens, it appears crucial that experiments be devised in which groups of animals treated with the various prophylactic regimens be simultaneously challenged with each inoculum size of the strain tested. This caution might not have been taken in the rabbit experiments and might explain some of the discrepancies between our results and the results of others.

Third, previous experiments in rats [6] have shown that protection against endocarditis is independent of the inoculum size only when the mechanism of 
protection is likely to be bacterial killing. This can occur when the bacteria are sensitive enough to the bactericidal action of the antibiotic that they are killed during the time they are exposed to the antibiotic in vivo. In the present experiments, it is unlikely that the combination of amoxicillin and gentamicin, despite its in vitro synergism against all six strains, killed the organisms fast enough in vivo to extend protection to inocula higher than the $\mathrm{ID}_{90}$. Indeed, it took $\geqslant 6 \mathrm{hr}$ for the antibiotic combination to kill all six strains in vitro, whereas serum levels of both antibiotics and bactericidal activities in vivo were undetectable by $6 \mathrm{hr}$. In contrast, experiments with $S$. sanguis in rabbits have been performed with procaine-penicillin $\mathrm{G}$, which, at $6 \mathrm{hr}$, produced serum levels as high as $3.4 \mu \mathrm{g} / \mathrm{ml}$ and produced high bactericidal titers when combined with streptomycin [17]. Thus, pharmacokinetic differences of antibiotics in rat and in rabbit experiments might be additional factors that explain the different results observed between our experiments and those of others.

The mechanisms by which antibiotics afforded protection in the present observations are not clear. Experiments from different laboratories have demonstrated that protection against endocarditis might occur in the absence of bacterial killing and suggested that other mechanisms of protection, such as inhibition of bacterial adherence onto damaged valves, might play a role $[6,19-21]$. This may also be the case in the present experiments, which showed that amoxicillin inhibited the in vitro adhesion to platelet-fibrin matrices of all strains tested, including the two enterococcal strains (data not shown). Inhibition of bacterial adherence conferred by amoxicillin alone was not enhanced by the addition of gentamicin for three of the four streptococcal strains tested (data not shown). Therefore, if inhibition of adherence was a mechanism by which antibiotics protected against endocarditis, one could have predicted from in vitro adhesion experiments that the combination of amoxicillin and gentamicin would not be more effective than amoxicillin alone in vivo, a prediction confirmed in the present rat experiments.

In conclusion, in our model single doses of amoxicillin were as effective in preventing enterococcal endocarditis as they were in preventing endocarditis due to various streptococcal strains. Protection, however, was limited to inocula of moderate size, especially for S. faecalis, and was probably not conferred by killing of the bacteria. Single doses of the synergistic combination of amoxicillin and gentamicin were not more effective in preventing endocarditis than was amoxicillin alone, probably because the combination did not kill the bacteria used for challenge in this model rapidly enough to be operative by this mechanism.

Certain authors [7] recommend single doses of amoxicillin for the prevention of streptococcal endocarditis, combining it with a single dose of an aminoglycoside for high-risk patients. The present experiments, as well as other recent studies [6], show that a single dose of amoxicillin is effective in preventing experimental streptococcal, including enterococcal, endocarditis. Our data suggest, however, that a single dose of a synergistic combination of antibiotics might not be significantly more effective than a single dose of amoxicillin alone. Recent experiments in rats have confirmed previous studies in rabbits by Durack et al. [2] and by Pelletier et al. [3] and have shown that only multiple doses of a combination of antibiotics given for at least $48 \mathrm{hr}$ can ensure inoculum-independent protection [22]. Therefore, patients in whom the development of bacterial endocarditis would be disastrous (e.g., patients with prosthetic valves) might benefit from multiple doses of a combination of antibiotics to minimize the risk of subsequent endocarditis. Similar regimens might also be recommended when one intends to prevent endocarditis caused by $S$. faecalis, because the capacity of these organisms to induce endocarditis appears particularly high in view of the low $\mathrm{ID}_{90}$; a single dose of an antibiotic or of a combination of antibiotics might not provide a sufficient margin of safety even for a patient at moderate risk of developing endocarditis.

\section{References}

1. Kaplan EL, Anthony BF, Bisno A, Durack DT, Houser H, Millard HD, Sanford J, Shulman ST, Stillerman M, Taranta A, Wenger N. Prevention of bacterial endocarditis. Circulation 1977;56:139A-43A

2. Durack DT, Petersdorf RG. Chemotherapy of experimental streptococcal endocarditis. 1. Comparison of commonly recommended prophylactic regimens. J Clin Invest 1973;52:592-8

3. Pelletier LL Jr, Durack DT, Petersdorf RG. Chemotherapy of experimental streptococcal endocarditis. IV. Further observations on prophylaxis. J Clin Invest 1975;56:319-30

4. Petersdorf RG. Antimicrobial prophylaxis of bacterial endocarditis. Prudent caution or bacterial overkill? Am J Med 1978;65:220-3 
5. Glauser MP, Francioli P. Successful prophylaxis against experimental streptococcal endocarditis with bacteriostatic antibiotics. J Infect Dis 1982;146:806-10

6. Glauser MP, Bernard JP, Moreillon P, Francioli P. Successful single-dose amoxicillin prophylaxis against experimental streptococcal endocarditis: evidence for two mechanisms of protection. J Infect Dis 1983;147:568-75

7. Simmons NA, Cawson RA, Clarke C, Eykyn SJ, McGowan DA, Oakley CM, Shanson DC. The antibiotic prophylaxis of infective endocarditis. Lancet 1982;2:1323-6

8. Moellering RC Jr, Krogstad DJ. Antibiotic resistance in enterococci. In: Schlessinger D, ed. Microbiology. Washington, DC: American Society for Microbiology, 1979:293-8

9. Washington JA II, Sutter VL. Dilution susceptibility test: agar and macro-broth dilution procedures. In: Lennette $\mathrm{EH}$, Balows A, Hausler WJ Jr, Truant JP, eds. Manual of clinical microbiology. 3rd ed. Washington, DC: American Society for Microbiology, 1980:453-8

10. Shanson DC, Ashford RFU, Singh J. High-dose oral amoxycillin for preventing endocarditis. Br Med J 1980;1:445-6

11. Siber GR, Echeverria P, Smith AL, Paisley JW, Smith DH. Pharmacokinetics of gentamicin in children and adults. J Infect Dis 1975;132:637-51

12. Sabath LD, Anhalt JP. Assay of antimicrobics. In: Lennette EH, Balows A, Hausler WJ Jr, Truant JP, eds. Manual of clinical microbiology. 3rd ed. Washington, DC: American Society for Microbiology, 1980:485-90

13. Anhalt JP, Sabath LD, Barry AL. Special tests: bactericidal activity, activity of antimicrobics in combination and detection of $\beta$-lactamase production. In: Lennette EH, Balows A, Hausler WJ Jr, Truant JP, eds. Manual of clinical microbiology, 3rd ed. Washington, DC: American Society for Microbiology, 1980:478-84

14. Herief E, Glauser MP, Freedman LR. Vancomycin prophylaxis of streptococcal endocarditis in rats. In: Nelson JD, Grassi C, eds. Current chemotherapy and infectious dis- ease. Vol 2. Washington, DC: American Society for Microbiology, 1980:911-13

15. Glauser MP, Francioli P, Meylan $\mathrm{P}$, Moreillon $\mathrm{Ph}$, Heraief E. Antibiotic prophylaxis for patients with prosthetic valves. Lancet 1983;1:237-8

16. Durack DT, Starkebaum MK, Petersdorf RG. Chemotherapy of experimental streptococcal endocarditis. VI. Prevention of enterococcal endocarditis. J Lab Clin Med 1977;90:171-9

17. Hess J, Dankert J, Durack D. Significance of penicillin tolerance in vivo: prevention of experimental Streptococcus sanguis endocarditis. J Antimicrob Chemother 1983;11:555-64

18. Guze PA, Kalmanson GM, Freedman LR, Ishida K, Guze LB. Antibiotic prophylaxis against streptomycin-resistant and -susceptible Streptococcus faecalis endocarditis in rabbits. Antimicrob Agents Chemother 1983;24:514-17

19. Bernard J-P, Francioli P, Glauser MP. Vancomycin prophylaxis of experimental Streptococcus sanguis. Inhibition of bacterial adherence rather than bacterial killing. J Clin Invest 1981;68:1113-6

20. Scheld WM, Zak O, Vosbeck K, Sande MA. Bacterial adhesion in the pathogenesis of infective endocarditis. Effect of subinhibitory antibiotic concentrations on streptococcal adhesion in vitro and the development of endocarditis in rabbits. J Clin Invest 1981;68:1381-4

21. Lowy FD, Chang DS, Neuhaus EG, Horne DS, Tomasz A, Steigbigel NH. Effect of penicillin on the adherence of Streptococcus sanguis in vitro and in the rabbit model of endocarditis. J Clin Invest 1983;71:668-75

22. Glauser MP, Moreillon PH, Francioli P. Comparison of single versus multiple doses of amoxicillin and amoxicillin + gentamicin in the prophylaxis of streptococcal endocarditis in rats [abstract no. 865]. In: Program and abstracts of the 23rd Interscience Conference on Antimicrobial Agents and Chemotherapy. Washington, DC: American Society for Microbiology, 1983. 